\title{
El estudio del derecho desde un enfoque complejo y transdisciplinar: experiencias de investigación en políticas de juventud en Argentina
}

The study of law from a complex and transdisciplinary approach:

Research experiences in youth policies in Argentina

\author{
Yussef Becher \\ ORCID: 0000-0003-1256-3890 \\ Consejo Nacional de Investigaciones Científicas y Técnicas (Conicet), Universidad Nacional de San Luis (UNSL), \\ Argentina \\ Correo: yussefbe@gmail.com \\ Recibido: 09/07/2021
}

Aceptado: 29/07/2021

Resumen: La finalidad del artículo es ofrecer una propuesta conceptual sobre el derecho. Se recurre a una teoría epistemológica de trayectoria que conduce a observar la realidad desde su complejidad. Asimismo, conlleva ciertos presupuestos al momento de la construcción de la ciencia, en particular, su inter o transdisciplinariedad. La disciplina jurídica ha estado históricamente vinculada al positivismo, lo cual la aproximó, según ciertas posturas, a los cánones instituidos sobre lo académico. No obstante, se la critica por un supuesto distanciamiento de lo que sucede en situaciones o contextos sociales particulares. Además, se brindan resultados de investigación —en el marco de dos tesis de posgrado- que han incorporado aspectos de los antes enunciados a través del análisis de los efectos de regulaciones estatales sobre políticas sociales para jóvenes: la Asignación Universal por Hijo para Protección Social (AUH) y el Programa de Respaldo a Estudiantes Argentinos (Progresar). En consecuencia, la intención del aporte es propiciar saberes según un prisma socio-jurídico.

Palabras clave: estudio del derecho; complejidad; transdisciplinariedad; políticas sociales; juventudes.

\begin{abstract}
The purpose of the article is to offer a conceptual proposal on the law. An epistemological trajectory theory is used, that leads to observing reality from its complexity. Likewise, it entails certain assumptions at the time of the construction of science, in particular, it's inter or transdisciplinarity. The legal discipline has historically been linked to positivism, which, according to certain positions, brought it closer to the canons instituted on academics. However, it is criticized for an alleged distancing from what happens in particular social situations or contexts. In addition, research results are provided - in the framework of two postgraduate theses - that have incorporated aspects of the aforementioned through the analysis of the effects of state regulations on social policies for young people: The Asignación Universal por Hijo para Protección Social (AUH) and the Programa de Respaldo a Estudiantes Argentinos (Progresar). Consequently, the intention of the contribution is to promote knowledge from a sociolegal perspective.
\end{abstract}

Keywords: law study; complexity; transdisciplinarity; social policy; youths.

Cómo citar: Becher, Y. (2021). El estudio del derecho desde un enfoque complejo y transdisciplinar: experiencias de investigación en políticas de juventud en Argentina. Revista de Derecho, 24, 202-215. 


\section{Introducción}

El texto tiene como objetivo presentar una propuesta conceptual sobre el derecho. Para ello, se acude a una tradición epistemológica consolidada que plantea una forma de mirar la realidad según determinadas características: su multicausalidad, heterogeneidad y diversidad. Ello, a su vez, supone ciertos presupuestos al momento de la construcción y transmisión del saber científico, principalmente, su inter o transdisciplinariedad. ${ }^{1}$

El derecho, por su parte, se ha mostrado históricamente como una disciplina ligada al positivismo. Ello le ha reportado ventajas, pero también una severa crítica sobre un supuesto distanciamiento acerca de lo que sucede en situaciones o contextos particulares. En efecto, complejizar el sentido jurídico instituido podría conducir a alternativas científicas que contribuyan a vincular más al derecho con las prácticas sociales.

En ese sentido, se brindan algunos resultados obtenidos en el marco de dos tesis de posgrado que incorporan elementos que permiten analizar el efecto de regulaciones estatales —que enmarcan políticas sociales - en un colectivo particular: los jóvenes. En la primera de ellas, realizada en la Maestría en Sociedad e Instituciones (Facultad de Ciencias Económicas, Jurídicas y Sociales, FCEJS-UNSL), se indagó sobre la concepción de sujeto en dos programas sociales que tienen a las juventudes como destinatarias (directas o indirectas): la Asignación Universal por Hijo para Protección Social (AUH) y el Programa de Respaldo a Estudiantes Argentinos (Progresar).

Por otro lado, en una tesis posterior (aún en curso), en el Doctorado en Ciencias Sociales de la Facultad Latinoamericana de Ciencias Sociales (Flacso), se siguió investigando sobre subjetividades estatales y los efectos de las normativas, desde un abordaje empírico. Respecto de las acciones públicas anteriores, se continuó con el Progresar.

Por consiguiente, la intención de este aporte es estimular la construcción de conocimiento a partir de reconocer sus condiciones de posibilidad, según un prisma sociojurídico. Con tal finalidad, se invita a recorrer el camino que inicia a continuación.

\footnotetext{
${ }^{1}$ Si bien se adhiere al uso del lenguaje no sexista, en especial a través de barras que distinguen entre masculino y femenino, se decidió no utilizarlo de modo constante para propiciar una lectura más fluida.
} 


\section{El derecho y la epistemología de la complejidad: nexos posibles}

Cuando Edgar Morin (1998) explica su teoría apela a una situación de su vida cotidiana que, tal vez, en la academia se pueda compartir. Tras finalizar una conferencia se dispone a almorzar y, además, a organizar las distintas intervenciones del público sobre su ponencia. A partir de ello, intentar brindar algunas respuestas ordenadas que, sin embargo, permitieran "respetar la diversidad sin hacer un puro y simple catálogo" (p. $135)$.

He allí, quizá, uno de los desafíos actuales en la transmisión del conocimiento. Por una parte, la cotidianidad se manifiesta en tanto que ámbito heterogéneo de pluralidad de situaciones; mientras que, por otro lado, se requiere arribar a cierta síntesis cognitiva que haga posible la difusión de un saber esquemático. A aquello se suma, a su vez, las tradiciones que son propias de cada disciplina.

El derecho, en tanto que ciencia o saber homogéneo, surge ligado a prácticas que evidencian la dimensión del poder en su conformación. Jesús Vega (2009), en su estudio sobre la constitución histórica de la ciencia, refleja cómo lo jurídico se consolida como disciplina autónoma, dejando de lado cierto ropaje académico que lo disminuía a una técnica (durante la era antigua o medieval), a partir de la positivización y estatalización consumada en el siglo XIX. Entonces, "Producidas las codificaciones europeas, el ‘derecho' deja de identificarse con el ius commune de estirpe romano-canónica para pasar a ser el Derecho del Estado" (p. 387).

Por ende, esa tendencia positivista, si bien reportó sus beneficios en torno al afianzamiento científico de lo jurídico, también implicó su reducción a formalismos o rigorismos que aún perviven en las praxis investigativas. Aunque, tal como proponía Morin (1998), ya no es posible asumir una idea de la realidad disminuida a cierta lógica minimalista que renuncie a la potencia de observar los fenómenos sociales en su multiplicidad.

A partir de ello, adoptar una postura epistemológica de tales características trae aparejadas consecuencias al interior de la construcción de la ciencia. Quizá, como advertía el sociólogo francés, un primer conflicto deviene de la necesidad de "atravesar las disciplinas", pues ello supone enfrentamientos con "gente a la que podamos llamar especialistas” (p. 136). En rigor, la apuesta de esta concepción filosófica es por la inter o transdisciplinariedad que renuncia a los conocimientos compartimentados para interesarse por la polifonía que emerge de las diferentes disciplinas. 
Sin embargo, tal actitud intelectual no está exenta de dificultades, pues requiere aceptar, por una parte, cierta flexibilidad cognitiva y, como consecuencia de ello, la incertidumbre. Tal vez la emergencia sanitaria actual puso de nuevo en evidencia la relevancia de las emociones y, entre ellas, la antes mencionada. Sucede que la pandemia mostró la imposibilidad de planificar en función de certezas, pues la vida cotidiana se alteró por completo, en especial, dos de las dimensiones que la atraviesan: tiempo y espacio. Todas las personas se vieron obligadas, siempre que pudieran, a recurrir de modo más intenso que antes a los dispositivos tecnológicos. Si bien ya lo había anunciado Giddens (1994), a través del concepto de desenclave, el contexto reciente enfrentó de forma abrupta o inesperada a la modificación de la presencialidad como modo predominante de la interacción intersubjetiva.

Asimismo, se evidencian nuevos ejercicios de la vigilancia que redefinen a la siempre vieja y siempre actual idea de la biopolítica foucaultiana. Como señala Preciado (2020), el encierro en los hogares implicó la concentración de casi la totalidad de la actividad humana en dichos espacios, por lo tanto, el control adquirió otras connotaciones. El filósofo español advierte sobre la agudización, si bien con diferencias en la gestión de la crisis sanitaria en cada país, de modalidades farmacopornográficas de biovigilancia, como efecto de la "detección individual del virus a través de la multiplicación de los test y de la vigilancia digital constante y estricta de los enfermos a través de sus dispositivos informáticos móviles" (p. 177).

Por lo tanto, los escenarios sociales contemporáneos se diversifican cada vez más. La pandemia también acentuó desigualdades preexistentes que, como tales, estimularon resistencias o activismos colectivos y respuestas estatales. Todo ello pone el acento en la exigencia de un conocimiento que no descanse en la comodidad epistémica que supone considerar que ya se poseen los saberes necesarios; por el contrario, conlleva una actitud que supere la soberbia intelectual. "No se trata, hoy en día, de ensombrecerse en el apocalipsis y el milenarismo; se trata de ver que estamos, tal vez, al final de cierto tiempo y, esperémoslo, al comienzo de tiempos nuevos" (Morin, 1998, p. 164).

Otra arista de la discusión anterior la introduce el debate sobre la cientificidad del derecho. Rodríguez (2000) sintetiza tres posibles tendencias: a) el derecho como teoría; b) el derecho como técnica; c) el derecho como ciencia. En la primera de ellas, el objeto de estudio está determinado por la teoría general del derecho: "Es una suerte de propedéutica general relativa a los llamados 'conceptos jurídicos fundamentales', a la teoría de la ciencia del derecho, de las fuentes, de la interpretación, de la norma jurídica 
y del ordenamiento" (p. 64). Por ello, excede la normatividad y conduce a incluir las demás disciplinas jurídicas. Sin embargo, se cuestiona si es posible considerar objeto científico a una teoría general, por lo cual, como señalan quienes se enrolan en esa postura (Zuleta Puceiro), solo sería factible a través de la interdisciplinariedad.

Por otra parte, se hallan quienes definen lo jurídico como una técnica (Atienza, Bunge). Ello remite a un conjunto de procedimientos que usan las distintas personas operarias del sistema legal (jueces, abogados, ciudadanía, docentes) para sistematizar, interpretar y aplicar el derecho positivo vigente o no.

Por último, se ubican quienes conceptualizan al derecho en tanto que ciencia, lo cual supone una conexión estrecha con la dogmática jurídica. Se afirma que esta última es un saber esencialmente descriptivo, "basado en un conjunto de procedimientos abstractos, capaces de obtener, a partir de los materiales del derecho positivo, una red de 'instituciones' que, reagrupadas y ordenadas según criterios de coherencia interna, se constituyen en sistema" (Rodríguez, 2000, p. 67).

Vega (2009), si bien niega el carácter científico del saber jurídico, reconoce en la postura anterior la posibilidad de acercarlo a determinados requisitos académicos. Aunque asumiendo el costo que implica divorciar - parafraseando a Vilanova y Lértora Mendoza (1995) — la disciplina de la sociedad y, a partir de ello, ubicarla entre los objetos ideales, tal como ocurre con las matemáticas.

Ahora bien, ¿es posible sustentar la existencia de un único modelo epistemológico? La teoría de la complejidad plantea un concepto de paradigma científico en tanto que relación lógica (inclusión, conjunción, disyunción, exclusión) de un cierto número de nociones o categorías maestras (Morin, 1998). Por consiguiente, la consolidación de un saber impone una hegemonía que, a su vez, habilita conocimientos contrahegemónicos o bien que se construyen desde los márgenes.

En ese sentido, a veces lo académico se define según un conjunto de criterios instituidos, aunque - como señalaba el sociólogo francés- se pueden efectuar otros recorridos científicos, tal vez menos difundidos, pero que también ameritan intereses intelectuales. Entonces, lo dominante necesariamente excluye y, de allí, la oportunidad de hacer emerger esos saberes que se producen por fuera de los espacios que poseen mayor reconocimiento.

A partir de ello, no es dable brindar una respuesta conclusiva sobre el carácter científico de lo jurídico, pues, tal como sucede con otras ciencias sociales, el modelo con el que se contrasta es uno, pero no el único. Sin embargo, es preciso desde el enfoque 
complejo renunciar a toda intención de reducir el derecho a meros rigorismos formales que no reparen en sus efectos sobre las tramas sociales. Por lo tanto, las divergencias sobre la relación entre la ciencia y el mundo de lo jurídico, más allá de los sesgos positivistas evidenciados tanto en una como otra esfera, no tendrían que conllevar a negar su fuerza como fenómeno social.

Lo anterior, además, incide sobre las praxis investigativas. Si bien existen distintas metodologías jurídicas (tales como la hermenéutica y la dogmática), la socio-jurídica es la que permite mostrar, en sentido amplio, el impacto del derecho en la sociedad. Para ello, se recurre a categorías de diferentes disciplinas (sociología, antropología, filosofía, psicología y sus cruces específicos con el derecho; Sánchez Zorrilla, 2011). En un trabajo previo (Becher, 2017a), se evidenció cómo en tiempos recientes dicha perspectiva ha ido ganando su espacio en las propuestas de investigación. Si bien la revisión de antecedentes abarcó dos ejes teóricos (género y políticas sociales), el acento estuvo puesto, también, en identificar aquellos conceptos en torno a los cuales se hizo posible estudiar la influencia de lo jurídico en grupos o sectores sociales.

En consecuencia, se reconoció que las categorías de significados y prácticas propiciaron marcos teóricos rigurosos y de amplia trayectoria en las ciencias sociales, para posibilitar los análisis según un prisma socio-jurídico. En el próximo apartado, se mostrará la forma concreta que adquirieron en dos investigaciones enmarcadas en tesis de posgrado.

\section{La teoría en movimiento}

En la primera investigación (tesis de maestría) se buscó conocer la concepción de sujeto, según las regulaciones normativas, en dos programas sociales nacionales dirigidos a jóvenes: la AUH y el Progresar. Se trata de dos políticas de transferencias condicionadas. Ello implica que mensualmente se transfiere parte de un monto en efectivo (80\%) a las personas receptoras, mientras que el resto $(20 \%)$ se retiene hasta que la administración pública corrobora el cumplimiento de las condicionalidades en salud o educación.

La AUH se implementa en Argentina desde el año 2009 y se creó a través del decreto 1602/09. El programa brinda protección social a niños y jóvenes menores de 18 años (o sin límite de edad en caso de discapacidad) de personas desocupadas o con trabajos informales que no superen el salario mínimo. A partir de ello, contribuyó a la universalización de las asignaciones familiares, antes circunscriptas a empleados en condiciones de formalidad laboral. 
El Progresar, por su parte, se comenzó a ejecutar desde el año 2014 a través del decreto 84/14 y se modificó, algunos meses después, por el decreto 505/15. La política permite el inicio o la continuidad de los estudios, en todos sus niveles, o experiencias laborales formativas para jóvenes de entre 18 y 24 años, cuyos ingresos no excedan tres salarios mínimos.

En la indagación efectuada en la maestría, se recurrió a una estrategia metodológica cualitativa y de análisis documental, que permitió comprender las concepciones que las regulaciones normativas de los programas sustentan sobre las poblaciones a las que se dirigen. El paradigma cualitativo hizo posible identificar y distinguir tipologías históricas de clasificación de los sujetos de las políticas sociales según diferentes contextos. De modo que en la década de los 90, como consecuencia del modelo de gobierno neoliberal, surgió una forma de considerar al destinatario de la política social como beneficiario o receptor de la asistencia del Estado.

Por otro lado, desde inicios del nuevo siglo, en el marco de políticas públicas progresistas, se empezó a modificar la concepción anterior tras la irrupción del enfoque de derechos humanos, de acuerdo a los Objetivos de Desarrollo del Milenio de las Naciones Unidas. Si bien cada país de la región canalizó de modo diferente dicho enfoque, en Argentina adquirió la forma de intervenciones sociales públicas. Entre ellas, los programas antes mencionados.

Sin embargo, muchas veces los derechos humanos consolidan retóricas o narrativas atractivas para los gobiernos que no logran integrarse por completo en sus acciones. De allí que si bien los dos programas que se incluyeron en la investigación iniciaron su recorrido en un tiempo más propicio para la puesta en marcha de políticas según una perspectiva de derechos, es preciso profundizar en los modos de regulación estatales para analizarlos científicamente.

Entonces, se emprendió tal tarea a través del estudio de las normativas que dieron origen a la AUH y el Progresar con la finalidad de conocer los sentidos o significados que construyen respecto del ciudadano joven. Vale aclarar que no se trató de una exégesis acerca del contenido de las normas, pues el análisis documental consistió en una interpretación hermenéutica. Por lo cual, a partir del ejercicio anterior de distinción de modos históricos de construcción de subjetividades estatales en políticas sociales, se escudriñó la configuración específica que adquiría en cada programa.

A partir de lo anterior, se identificó en la AUH una interpelación a su destinatario en tanto que receptor. Ello se corresponde con el esquema típico de las transferencias 
condicionadas, en donde una parte recibe un monto de dinero y la otra cumple con la condicionalidad. Aunque no se reduce a dicho aspecto, pues es propio de toda política que tiene esa característica, sino que la figura del receptor emerge con mayor fuerza según una diferencia concreta entre las tareas o trabajos que se asignan a cada uno de los polos de la relación legal que se demarca.

Por un lado, se establecen específicas cargas de cuidado para los padres respecto de sus hijos/as, quienes tienen que realizar los controles de salud, según lo señalado en el artículo 6 del decreto 1602/09, desde los 0 hasta los 4 años, y desde los 5 años se exige el ingreso a instituciones educativas públicas. Todo ello con la finalidad de garantizar derechos para los infantes a cargo, pues si bien el adulto percibe la transferencia de ingresos tiene la obligación de facilitar la inclusión de su hijo/a en lo relativo a la salud o la educación.

En consecuencia, según el esquema de implementación operativa de la AUH, y además lo comprueba la normativa, se enaltece la figura del receptor como garante de derechos para los infantes. Si bien en la tesis de maestría no se profundizó al respecto, es factible reconocer que no se incluye a la persona joven en un rol relevante respecto de decisiones que podrían involucrarla. Por ese motivo, también, solo se reconoció la presencia de un adulto como actor clave para lograr la inclusión de los/as niños/as y jóvenes destinarios/as del programa.

Por otra parte, en el Progresar se advirtió una significación acerca del ciudadano joven más próxima a considerarlo sujeto de derechos. Ello se vincula con cierta tendencia a la progresividad de la medida que se evidenció tras un año de su implementación. El programa comenzó con una focalización más estricta (decreto 84/14), mientras que luego flexibilizó dicho criterio al incrementar el tope salarial de uno a tres montos mínimos a través del decreto 505/15.

Asimismo, en su regulación normativa inicial el Progresar contiene disposiciones tendientes a lograr una adecuada coordinación ministerial entre las áreas de gobierno involucradas, como también entre nación y las provincias (arts. 13 y 14 del decreto 84/14). Hasta el año 2015, el programa se ejecutó en el ámbito de la Administración Nacional de la Seguridad Social (Anses) — al igual que la AUH - lo cual implicaba, a diferencia de acciones estatales anteriores, estar inserto en el espacio donde se gestionan los derechos por contingencias (tales como enfermedad o vejez) de los trabajadores/as formales.

Además, el Progresar incorpora mecanismos de supervisión sobre su gestión a través de un Comité Ejecutivo, integrado por representantes de la Jefatura del Gabinete de 
Ministros, el Ministerio de Economía y Anses (art. 11 del decreto 84/14). Esta decisión, sumada a la inclusión en el organismo de la seguridad social y la articulación entre diferentes niveles de gobierno, se traduce en una mayor institucionalización y, al mismo tiempo, distancia al Progresar de políticas de corte asistencialista que se implementan directamente desde los ministerios. ${ }^{2}$

En una investigación posterior (tesis de doctorado), se continuó ahondando en torno a la construcción de subjetividades estatales, pero desde un abordaje empírico. En cuanto a los programas sociales, si bien se incluyó otro sobre empleo juvenil, de los antes descriptos se siguió con el Progresar. De modo que algunos de los aspectos antes analizados pudieron ser estudiados desde la perspectiva de las personas jóvenes destinatarias.

En relación con la estrategia metodológica, el análisis documental perdió un poco su protagonismo para dar paso a entrevistas en profundidad - individuales y grupales - y observación participante. Por consiguiente, no solo se examinaron significados o sentidos construidos en torno al programa, sino también las prácticas de los/as jóvenes respecto de otros integrantes del mismo y la administración pública (Anses).

Por ende, en la tesis si bien se reparó en distintas dimensiones del objetivo propuesto, acá se pretende señalar aquellos que permiten comprender las implicancias para los/as jóvenes de modificaciones normativas suscitadas tras el cambio de Gobierno a nivel nacional en el año 2015, que quedó a cargo de la alianza política Cambiemos. En primer lugar, es preciso mencionar que tales reformas sobre el Progresar se formalizaron en 2018, sin embargo, ya estaban presente en las reglas burocráticas que se empezaron a aplicar dos años antes.

En los vínculos que las personas destinatarias del Progresar mantuvieron con Anses, una de las primeras dificultades estuvo asociada al cumplimiento de la condicionalidad. Como se dijo, la condición del programa consistía en la asistencia a instituciones de diferente nivel educativo según corresponda. Para los estudiantes universitarios, con quienes principalmente se llevó a cabo la investigación, se trataba de mantener la regularidad aprobando dos asignaturas por año. A partir de ello, que varios jóvenes vivenciaran la contraprestación del programa con espontaneidad, pues no imponía una obligación distinta de la que ya tenían que cumplir como alumnos de una carrera de grado.

\footnotetext{
${ }^{2}$ Se puede continuar conociendo sobre dicho estudio en Becher (2017b) y Becher (2017c). También en esos textos se citan las referencias teóricas que fueron necesarias para la construcción de las categorías analíticas y el enfoque metodológico.
} 
Según se registró en la tesis, tal circunstancia acercaba al Progresar a un cierto imaginario ligado al discurso de los derechos humanos en tanto que prerrogativas garantizadas para todos los ciudadanos.

Desde el año 2016, lo cual se objetivó en el anexo de la resolución del Ministerio de Educación 138/18, se empezó a exigir el 50 \% de las materias aprobadas por año de carrera. En rigor, dicha exigencia motivó la exclusión de muchos jóvenes que no cumplían con tal requisito, pues no solo se aplicó a quienes solicitaban el ingreso al Progresar por primera vez, sino también a quienes ya estaban insertos en él. Aunque en dicho caso se otorgó una prórroga de casi un año para adecuar la situación académica a la nueva disposición normativa. A pesar de ello, entre 2016-2017 se produjo una disminución de alrededor de doscientos mil destinatarios (Lombardía, 2017; Anses \& OSS, 2018; Bertranou, Jiménez \& Jiménez, 2018).

La resolución ministerial antes aludida también introdujo un premio para quienes aprobaran el $100 \%$ de las materias según el año correspondiente con un promedio igual o superior a 8. Además de distinciones por carreras estratégicas, en donde se priorizaba a las denominadas ciencias exactas por sobre las sociales.

Por cierto, los criterios de regularidad diferentes a los de las universidades públicas, junto al otorgamiento de una distinción por desempeño académico, implantó lógicas meritocráticas que fueron desvirtuando algunos de los fundamentos que motivaron la creación del Progresar. Pues el acento estaba puesto en la situación de vulnerabilidad de los/as jóvenes y la inclusión a través del empleo y la educación. Como se señala en el decreto 84-14:

La problemática juvenil tiene múltiples facetas que deben ser contempladas a la hora de abordar la temática, evitando caer en categorizaciones simplificadas y estigmatizantes, entre las que pueden mencionarse la necesidad de un acceso real y flexible a la oferta educativa, la provisión de estrategias públicas de cuidado para los jóvenes que tienen niños a cargo y el acompañamiento en una inserción laboral de calidad.

También es dable advertir que las modificaciones realizadas al programa tuvieron lugar en un contexto de crisis económica que afectó de manera significativa las posibilidades de empleo de las personas jóvenes. Casi llegando al final de la gestión de Cambiemos, los indicadores de desempleo en adultos se acercaban a los dos dígitos, mientras que para las juventudes rondaba el $30 \%$ (Bertranou et. al., 2018 según datos de 
la Encuesta Permanente de Hogares (EPH) del Instituto Nacional de Estadística y Censos (Indec). Sumado a ello, la inflación en productos alimentarios que arribaba al $50 \%$ anual para el 2019 (ODSA \& UCA, 2020).

En ese sentido, las regulaciones formalizadas en 2018 desnaturalizan los argumentos que motivaron el origen del Progresar, por cuanto agregan requisitos académicomeritocráticos en un marco en donde la situación socio-económica podría haber dificultado el desempeño juvenil en materia educativa. Varios de ellos, como se pudo relevar en la indagación doctoral, abandonaron sus estudios para aportar a las economías familiares. Asimismo, dado que tuvieron que restringir gastos, los montos destinados a fotocopias o transporte - desde sus residencias a los campus universitariosdisminuyeron. Esto incidió en la cantidad de materias que lograban regularizar por año.

En consecuencia, las reformas introducidas en el programa desde 2016 tuvieron un impacto a nivel de la construcción de las subjetividades juveniles. Si bien en este texto solo se mencionaron algunas de las significaciones y prácticas burocráticas que influyeron en las relaciones de los/as jóvenes con Anses, se identificó en la tesis entre algunos de los destinatarios una retórica que empezó a diferenciar al Progresar de aquella connotación en torno a los derechos que lo caracterizó inicialmente, para asemejarlo a la asistencia estatal típica de otros tiempos de la historia argentina. ${ }^{3}$

\section{Conclusión}

Asumir una perspectiva compleja ante el estudio del derecho supone iniciar un recorrido en donde, tal vez, haya que desandar lo transitado. Sin embargo, tal actitud deviene necesaria ante un mundo cada vez más diverso e influenciado por múltiples contextos que traspasan — tal como hizo notorio la pandemia — los límites concretos del tiempo y el espacio presencial. A su vez, con la incidencia de desigualdades previas y otras nuevas.

Por consiguiente, la discusión sobre el carácter científico de lo jurídico también motivó distintos debates. Aquí, más allá del posicionamiento que se adopte, el aporte de la epistemología de la complejidad es evitar toda intención de reducir el derecho a lo meramente normado o positivizado, y en consecuencia apostar por su estudio a partir del efecto que produce en las tramas sociales.

\footnotetext{
${ }^{3}$ Para continuar conociendo sobre la investigación, se pueden consultar los siguientes textos: Becher (2018) y Becher (2019). También allí se hallan las referencias teórico-metodológicas.
} 
Ello amerita recurrir a categorías de otras tradiciones teóricas, de allí su sentido transdisciplinar, que permita dar cuenta del impacto del mundo jurídico en la urdimbre de sentidos construidos en torno a las prácticas sociales. En ese sentido, se apeló a dos investigaciones (enmarcadas en tesis de posgrado) para reflejar la posibilidad de llevar a cabo indagaciones desde dicho enfoque teórico.

En la primera de ellas, se buceó en la concepción de sujeto en dos programas sociales (AUH y Progresar), según sus regulaciones normativas, que tienen a personas jóvenes como destinatarias. En la AUH se reconoció la presencia de un receptor adulto que es significado como garante de derechos para sus hijos/as, a quienes no se les asigna un rol relevante en decisiones que podrían involucrarlos/as.

Por otro lado, en el Progresar se advirtió mayor proximidad a la construcción del joven como sujeto de derechos. Ello se asocia con cierta tendencia a la progresividad de la medida a través de la flexibilización de topes salariales, que ampliaron los criterios de focalización, una adecuada coordinación ministerial y mecanismos de supervisión sobre la gestión del programa.

En la tesis doctoral, aún en curso, se continuó analizando la configuración de subjetividades estatales en el Progresar, pero, a diferencia de la anterior, desde un abordaje empírico. Se tuvieron en cuenta los efectos para los/as jóvenes de modificaciones normativas suscitadas en 2016, aunque fueron formalizadas dos años después.

Las principales dificultades surgieron en torno a los vínculos de las personas destinatarias con Anses en relación con el cumplimiento de las condicionalidades. Desde sus comienzos, el programa hizo coincidir su exigencia académica con el criterio de regularidad de la mayoría de las universidades públicas, mientras que en 2016 se empezó a requerir aprobar el $50 \%$ de las materias según año de cursada. Además, se estableció un premio y distinciones por carreras estratégicas.

Lo anterior fue distanciando al Progresar de cierta connotación en torno a los derechos que predominaba entre las juventudes. En su lugar, se instauraron lógicas meritocráticas en un contexto de crisis social que dificultó para muchos destinatarios como se evidenció en el estudio realizado - la continuidad de sus carreras de grado.

Por lo cual, es posible realizar investigaciones según un prisma socio-jurídico que desde un enfoque complejo de la realidad intenten dar cuenta de las implicancias de las normativas o regulaciones del derecho en colectivos o sujetos sociales concretos. 


\section{Referencias}

Administración Nacional de la Seguridad Social [Anses] \& Observatorio de la Seguridad Social [OSS]. (2018). Información sobre destinatarios del Programa de Respaldo a Estudiantes Argentinos (Progresar). Recuperado de http://observatorio.anses.gob.ar/

Becher, Y. (2017a). Hacia la construcción de un enfoque sociojurídico en el análisis de la producción cultural del género y las políticas sociales en la(s) juventud(es). Millcayac - Revista Digital de Ciencias Sociales, 4(6), 125-146. Recuperado de https://revistas.uncu.edu.ar/ojs/index.php/millca-digital/article/view/885/535

Becher, Y. (2017b). Cartografías socio-estatales y subjetividades. Un recorrido sobre programas sociales en la contemporaneidad. Buenos Aires: Teseo.

Becher, Y. (2017c). Políticas sociales y subjetividad: Un análisis socio-histórico sobre la concepción de sujeto. Kairós. Revista de Temas Sociales, 21(39), 1-19.

Recuperado de http://www.revistakairos.org/wpcontent/uploads/BecherKairos39.pdf

Becher, Y. (2018). Las juventudes y su vínculo con la burocracia estatal: entre marcas generacionales y redes de sociabilidad. En G. Castro (comp.), Militancias y políticas juveniles. Involucramientos sociales en contextos provinciales (281319). Buenos Aires: Teseo.

Becher, Y. (2019). El devenir femenino juvenil en programas sociales. De Prácticas y Discursos. Cuaderno de Ciencias Sociales, 8(12), 195-214.

Bertranou, F., Jiménez, M. \& Jiménez, M. (2018). Trayectorias hacia la formalización y el trabajo decente de los jóvenes en Argentina. Documento de Trabajo $\mathrm{N}^{\mathrm{o}} 18$. Oficina de país de la OIT para Argentina.

Giddens, A. (1994). Consecuencias de la modernidad. España: Alianza.

Lombardía, M. L. (2017) ¿PROG.R.ES.AR... o volver al pasado? II Convocatoria para la Divulgación Científica sobre Marginaciones Sociales. Programa Interdisciplinario de la UBA sobre Marginaciones Sociales (Piubamas).

Morin, E. (1998). Introducción al pensamiento complejo. Barcelona: Gedisa.

Observatorio de la Deuda Social Argentina [ODSA] \& Universidad Católica Argentina [UCA]. (2020). La pobreza como privación más allá de los ingresos (20102019). Introducción de datos fundados en un enfoque de derechos. Buenos Aires: Educa.

Preciado, P. B. (2020). Aprendiendo del virus. En Sopa de Wuhan. Pensamiento contemporáneo en tiempos de pandemias (163-185). Buenos Aires: ASPO.

Rodríguez, A. (2000). Acerca de la cientificidad del derecho. En M. del C. Schilardi y colaboradas (comp.), Ciencia y Derecho. La investigación jurídica. Mendoza: Editorial de la Universidad Nacional de Cuyo. 
Sánchez Zorilla, M. (2011). La metodología en la investigación jurídica: características peculiares y pautas generales para investigar en el derecho. Revista Telemática de Filosofía del Derecho, 14, 317-335.

Vega, J. (2009). Las calificaciones del saber jurídico y la pretensión de racionalidad del derecho. Doxa. Cuadernos de Filosofía del Derecho, 32, 375-414.

Vilanova, J. \& Lértora Mendoza, C. (1995). La dogmática, ciencia social. Replanteo del iuspositivismo realista. E.D., XXXIII (8699). Buenos Aires.

\section{Contribución autoral}

a) Concepción y diseño del trabajo; b) Adquisición de datos; c) Análisis e interpretación de datos; d) Redacción del manuscrito; e) revisión crítica del manuscrito.

Y. B. ha contribuido en $a, b, c, d, e$.

Editora científica responsable: Dra. María Paula Garat. 